\title{
Review
}

Journal of Innate
Immunity

\section{Roles of Heparin-Binding Protein in Bacterial Infections}

\author{
Adam Linder $^{\mathrm{a}}$ Oliver Soehnlein ${ }^{\mathrm{b}}$ Per Åkesson ${ }^{\mathrm{a}}$ \\ ${ }^{a}$ Department of Clinical Sciences, Division of Infection Medicine, Lund University, Lund, Sweden; \\ ${ }^{\mathrm{b}}$ Institute for Molecular Cardiovascular Research, RWTH Aachen University, Aachen, Germany
}

\section{Key Words}

Bacterial infection $\cdot$ Heparin-binding protein $\cdot$ Infectious diseases $\cdot$ Neutrophils $\cdot$ Streptococcus $\cdot$ Vascular leakage fection. In conclusion, this protein is strongly involved in the pathophysiology of severe bacterial infections, and thus represents a potential diagnostic marker and a target for treatment.

Copyright $\odot 2010$ S. Karger AG, Basel

\begin{abstract}
Infectious diseases remain a major health problem, where sepsis and other severe infectious diseases are common causes of morbidity and mortality. The importance of early and appropriate treatment of sepsis and severe bacterial infections has been underlined by the successes of measures like the Surviving Sepsis Campaign, among others. Thus, there is a need for clinical and laboratory tools to identify a patient with severe infection early and to distinguish between bacterial and non-bacterial conditions. Heparin-binding protein (HBP) is also called azurocidin, or cationic antimicrobial protein of $37 \mathrm{kDa}$ (CAP37). It is a multifunctional granule-associated protein that is rapidly mobilized from migrating polymorphonuclear leukocytes. HBP acts as a chemoattractant, an activator of monocytes and macrophages, and induces vascular leakage and edema formation. The release of HBP is triggered by ligation of neutrophilic $\beta_{2}$-integrins, a process that may be initiated by bacterial structures. The overall outcome is powerful vascular leakage. It has been shown that patients with severe sepsis express high levels of HBP in plasma before they develop hypotension. $\mathrm{HBP}$ is also involved in the pathophysiology of soft tissue in-
\end{abstract}

\section{Introduction}

\section{Sepsis and Severe Infections}

Infectious disease remains a major problem in global healthcare, and sepsis is a common cause of morbidity and mortality in hospitals [1]. It is the second leading cause of death in non-coronary intensive care units (ICUs) and the tenth leading cause of death in the United States [2]. Furthermore, the growing number of elderly and immunosuppressed persons represents a population with a high risk of acquiring sepsis, which is associated with organ failure and a high mortality rate. One of the diagnostic challenges is to identify at-risk patients before the stage where they need surveillance and treatment in an ICU. Thus it is of vital importance to detect severe infections and sepsis at an early stage and to improve treatment options. The pathophysiology of sepsis is a complex dynamic syndrome caused by disruption of the balance between pro- and anti-inflammatory mechanisms [3]. Invading microorganisms or damaged tissue compo-

\section{KARGER}

Fax +41613061234

E-Mail karger@karger.ch

www.karger.com (c) 2010 S. Karger AG, Basel

$1662-811 X / 10 / 0025-0431 \$ 26.00 / 0$

Accessible online at:

www.karger.com/jin
Dr. Adam Linder

Department of Clinical Sciences, Division of Infection Medicine

Lund University Hospital

SE-221 85 Lund (Sweden)

Tel. +46 46171 309, Fax +46 46323 895, E-Mail adam.linder@skane.se 
nents can stimulate immune cells, leading to a release of proinflammatory cytokines, reactive oxygen species and enzymes (see below for mechanistic details). Sepsis is diagnosed by clinical and laboratory signs of systemic inflammation, including changes in body temperature, leukocytosis, tachypnea, and tachycardia. Severe sepsis is defined as impaired circulation (i.e. blood pressure drop) with or without organ failure, and septic shock is present when the circulatory failure is refractory to fluid resuscitation.

It has been shown that in patients with septic shock, mortality was correlated to the time between the fall in systolic blood pressure and the start of antibiotic treatment [4]. Standardized clinical and laboratory signs of systemic inflammation are neither sensitive nor specific enough to discriminate between sepsis and non-infectious causes of systemic inflammatory response syndrome (SIRS), such as trauma, pancreatitis, major surgery, and vasculitis. Unfortunately, there is no gold standard for diagnosing sepsis, as bacterial cultures may be negative in $30-50 \%$ of the patients because of, for example, antibiotic pretreatment or inadequate sampling. Moreover, results of microbiological culturing are not immediately available, and clinicians often administer broad-spectrum antibiotics pending the microbiological results. Some of the markers that have been suggested as early biomarkers of sepsis include procalcitonin, interleukin-6, lactate, and C-reactive protein. However, the diagnostic and prognostic accuracy of these tests have been questioned due to inconsistent and variable results depending on the severity of illness in the patient population [5].

\section{Heparin-Binding Protein}

Heparin-binding protein (HBP), also called azurocidin or cationic antimicrobial protein of $37 \mathrm{kDa}$ (CAP37), is a neutrophil-derived granule protein first isolated and identified in 1984 by Shafer et al. [6]. While initially of interest for its broad antimicrobial activities towards Gram-positive bacteria (e.g. Enterococcusfaecalis), Gramnegative bacteria (e.g. Escherichia coli) and Candida albicans, it soon became apparent that HBP held potent immune-modulating activities. Both antimicrobial and immune-modulating activities are also shared by other neutrophil granule proteins such as $\alpha$-defensins or LL-37 which are collectively termed alarmins $[7,8]$. HBP, however, possesses some features which make it unique among these proteins. In contrast to defensins or LL-37 which undergo only limited exocytosis following neutrophil activation, $\mathrm{HBP}$ is almost completely discharged into the extracellular environment. This may be favored by the atypical subcellular location of HBP. Unlike other granule proteins, HBP is stored in two different granule subsets, azurophilic/primary granules and secretory vesicles [9]. While the first of these is rather inert with a low propensity for release, the latter is rapidly mobilized upon neutrophil activation. Interestingly, HBP is the only granule protein secreted into the environment from secretory vesicles $[9,10]$ thus underlining its importance in inflammatory responses. Finally, unlike its close relatives cathepsin G, neutrophil elastase, and proteinase-3, HBP is proteolytically inactive. This lack of proteolytic activity is due to the replacement of His and Ser residues in the catalytic triad. Nevertheless, HBP has been shown to bind to protease inhibitors such as aprotinin [11], an interaction which was shown to, e.g., abrogate HBP-mediated permeability changes [12].

During the establishment phase of inflammation, neutrophils are usually recruited before monocytes. This series of events is causally related and in fact HBP plays an important role in the transition from neutrophil to monocyte efflux [13]. Secreted from emigrating neutrophils, HBP binds to endothelial glycocalyx and is presented to leukocytes in the blood stream (fig. 1). In this location, HBP activates monocytes rolling along the endothelium and ultimately induces stable monocyte arrest. Adhesion of monocytes is followed by transendothelial extravasation and directed migration to the site of injury. Like other neutrophil-derived antimicrobial polypeptides, HBP chemoattracts monocytes [14]. The monocyte-attracting ability of HBP is about $80-100 \%$ of that of formyl-methionyl-leucyl-phenylalanine (fMLP), a strong enhancer of monocyte chemotactic migration. The monocyte population in humans and mice, however, is heterogeneous [15] and the subset-specific effects of HBP were therefore examined in a recent study [13]. That analysis showed that HBP specifically attracts $\mathrm{Grl}^{+}$monocytes, a cell population that is characterized by its potent proinflammatory functions. These cells have other important functions in infectious diseases [16] as well as in the progression of chronic inflammatory processes [17].

Following extravasation, monocytes differentiate towards macrophages which contribute to regulation of the inflammatory process by clearing bacteria and releasing soluble mediators that attract and instruct neighboring cells. Interestingly, it has been shown that HBP partially controls some of these functions [18]. HBP preferably binds to $\beta_{2}$-integrins of monocytic cells thereby initiating intracellular signaling that ultimately results in release of chemokines and proinflammatory mediators 


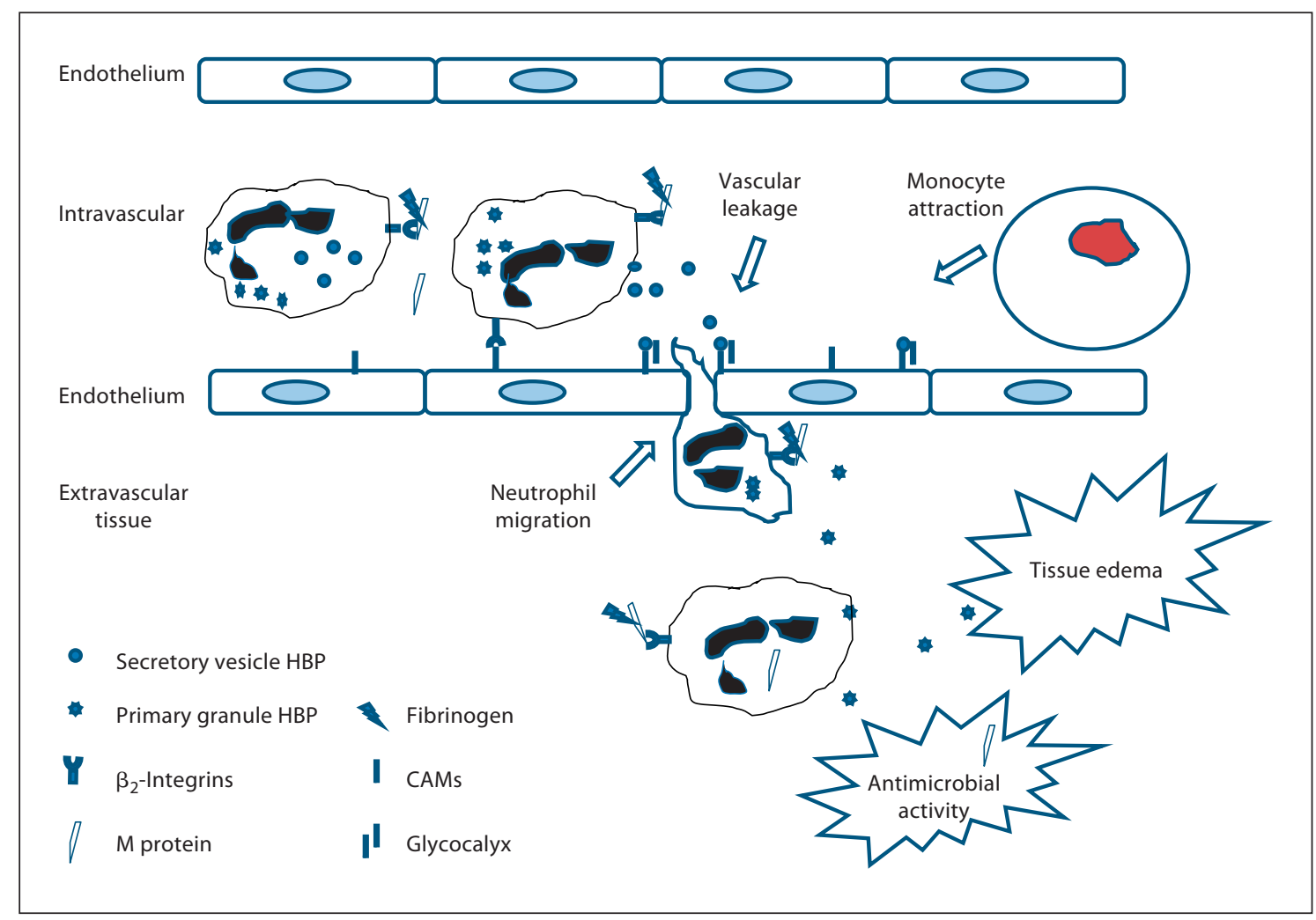

Fig. 1. Schematic overview of the effects of HBP in bacterial infections. S. pyogenes-derived M1 protein forms complexes with fibrinogen. These ligate neutrophilic $\beta_{2}$-integrin resulting in cellular activation and discharge of HBP from secretory vesicles. Due to charge interactions, HBP is deposited on endothelial cells where it induces increases in transendothelial permeability and edema formation. Furthermore, endothelial-bound HBP activates monocytes rolling along the endothelium promoting their firm arrest. Neutrophils migrated to the site of inflammation release HBP from primary granules which may primarily exert antimicrobial activities. In addition, HBP attracts inflammatory monocytes and activates macrophage antimicrobial activities.

[19]. The secretory products released by macrophages affect not only cells in close proximity, but they also activate macrophages in an autocrine fashion. Specifically, the HBP-triggered release of tumor necrosis factor and interferon- $\gamma$ by macrophages has been shown to induce phenotypic changes that are reminiscent of an M1 polarization pattern [20]. This phenotype is characterized by enhanced antimicrobial effectiveness and pronounced proinflammatory activity [21]. Alternatively, HBP may contribute to antimicrobial clearance by directly opsonizing bacteria, thus facilitating recognition and uptake by phagocytes [22]. Integrating these properties, HBP can be characterized as a proinflammatory protein, which is rapidly released from emigrating neutrophil. Much of its proinflammatory functions are based on activating monocytic cells, a mechanism that is also important in antimicrobial clearance.

Heparin-Binding Protein in Infections
This review will describe the role of HBP in severe bacterial infections, with focus on possible pathophysiological mechanisms, its diagnostic performance as a biomarker, and the potential use of HBP as a target of treatment.

\section{HBP as an Inducer of Endothelial Leakage}

In addition to monocytes, other cell types are also activated by HBP. In fact, endothelial cells are the first target of polymorphonuclear leukocyte-derived HBP released from secretory vesicles (fig. 1). Such interaction results in endothelial activation and subsequent de novo synthesis of cell adhesion molecules ultimately enhancing arrest of additional inflammatory cells [23]. In addition, impairment of the endothelial barrier function,

J Innate Immun 2010;2:431-438 
leading to plasma leakage and edema formation, is a characteristic feature of the inflammatory reaction. Previous studies clearly indicate that emigration of neutrophils is accompanied by efflux of plasma from the vasculature and that these cells are in a position to trigger permeability changes themselves $[24,25]$. Neutrophil adhesion and activation via $\beta_{2}$-integrins is of critical importance in neutrophil-evoked permeability increase [26]. Adhesion of neutrophils to endothelial cells induces rapid intracellular $\mathrm{Ca}^{2+}$-mobilization in both cell types, leading to granule exocytosis in the neutrophil and rearrangement of the endothelial cell cytoskeleton. Blockage of $\beta_{2}$-integrin function completely abrogates these responses [26]. Several of the granule proteins released were suggested to be critically involved in neutrophil-mediated permeability changes. Among these proteins are the members of the serprocidin family cathepsin G, elastase, proteinase-3 and the inactive serine protease HBP [27]. However, a series of seminal studies have identified HBP as the primary mediator of neutrophil-dependent permeability increases. Its location in rapidly mobilized secretory vesicles allows a rapid discharge upon neutrophil adhesion and activation. HBP could be demonstrated to provoke a rapid rise in cytosolic free $\mathrm{Ca}^{2+}$ in adjacent endothelial cells, formation of actin stress fibers, and increased paracellular permeability $[12,28]$. The responses to HBP stimulation are identical to those achieved by chemoattractant stimulation of neutrophils, and immunoneutralization of HBP in neutrophil-derived secretion completely inhibits the activity, substantiating the critical role of this protein in neutrophil-evoked alterations in vascular permeability. Interestingly, leukotriene B4 (LTB4)-mediated permeability requires LTB1 receptor activation on neutrophils, resulting in release of neutrophil HBP which triggers endothelial cell intracellular $\mathrm{Ca}^{2+}$ mobilization and increased endothelial permeability both in vitro and in vivo [28]. In addition to the importance of the localization of HBP in secretory vesicles, which allows an almost instant permeability change upon neutrophil adhesion, another feature of HBP is at least equally important in this process. HBP carries a large number of positively charged amino acid residues concentrated on one side of the protein, creating a strong dipole moment [29]. It is likely that the basic patch of HBP interacts with negatively charged proteoglycans on the endothelial cell surface by which endothelial cell conformational changes are induced. However, the exact mechanisms by which HBP activates signaling pathways in the endothelial cell and stimulates reorganization of cytoskeletal and junctional complexes remain elusive.

\section{Expression of HBP in Bacterial Skin Infections}

Necrotizing fasciitis (NF) is a severe streptococcal soft tissue infection characterized by a rapidly spreading destruction of deep skin layers and muscle fascia, often accompanied by circulatory and organ failure, the streptococcal toxic shock syndrome. Herwald et al. [30] demonstrated that complexes of M1 protein shed from the surface of Streptococcus pyogenes and human fibrinogen were present in the tissue from a patient with NF. It was also shown that M1/fibrinogen complexes activate neutrophils to degranulate and release HBP. In another study, tissue biopsies from patients with NF or severe cellulitis caused by $S$. pyogenes revealed that the recruitment of neutrophils and monocytes/macrophages to the infection focus is accompanied by the release of HBP [19]. $S$. pyogenes also causes a more common superficial skin infection, erysipelas. This infection is characterized by an intense inflammation of the skin with a painful erythematous rash and edema. In a study of 12 patients with erysipelas on one of the legs, HBP was present in skin biopsies obtained from infected and erythematous areas [31]. In contrast, HBP was not detectable in control biopsies from the non-infected leg. These studies suggest that the vasoactive HBP could play an important role in the edema formation seen in streptococcal skin infections. Lundqvist et al. [32] showed that HBP was present in much higher amounts in wound fluid from chronic ulcers as compared to acute ulcers. Culture supernatants of wound-derived Proteus mirabilis, E. faecalis and Pseudomonas aeruginosa induced a significant release of total HBP present in neutrophils. Furthermore, HBP was not degraded by $P$. aeruginosa elastase, a potent metalloproteinase that degrades antimicrobial peptides like LL-37. These findings indicate that HBP is stable in a highly proteolytic environment and that the effect of HBP on endothelial permeability and neutrophil recruitment may represent an early pathogenic step in ulcer development.

\section{Plasma Levels of HBP Are Increased in Severe Sepsis}

As mentioned above, HBP is a powerful inducer of vascular leakage [12] which is a typical sign of severe sepsis with resulting extravasation of plasma fluid and hypotension. It was demonstrated in a mouse model that streptococcal M1 protein, in complex with fibrinogen, activates neutrophils to degranulate and release proteins from all granule subsets, including HBP [33]. Degranulation of neutrophils was found to be causative of the sub- 
Fig. 2. Plasma levels of HBP at admission in 233 patients with fever and suspected infection. Each triangle represents the concentration in an individual plasma sample of HBP in the 5 patient groups. Bars represent the median of the values. The suggested cutoff value for HBP is marked at $15 \mathrm{ng} / \mathrm{ml}$. The triangles at 120 $\mathrm{ng} / \mathrm{ml}$ represent higher values in the septic shock group $(494,269,290$, and $182 \mathrm{ng} /$ $\mathrm{ml})$, and in the severe sepsis group (298 and $179 \mathrm{ng} / \mathrm{ml})$. SIRS = Systemic inflammatory response syndrome.

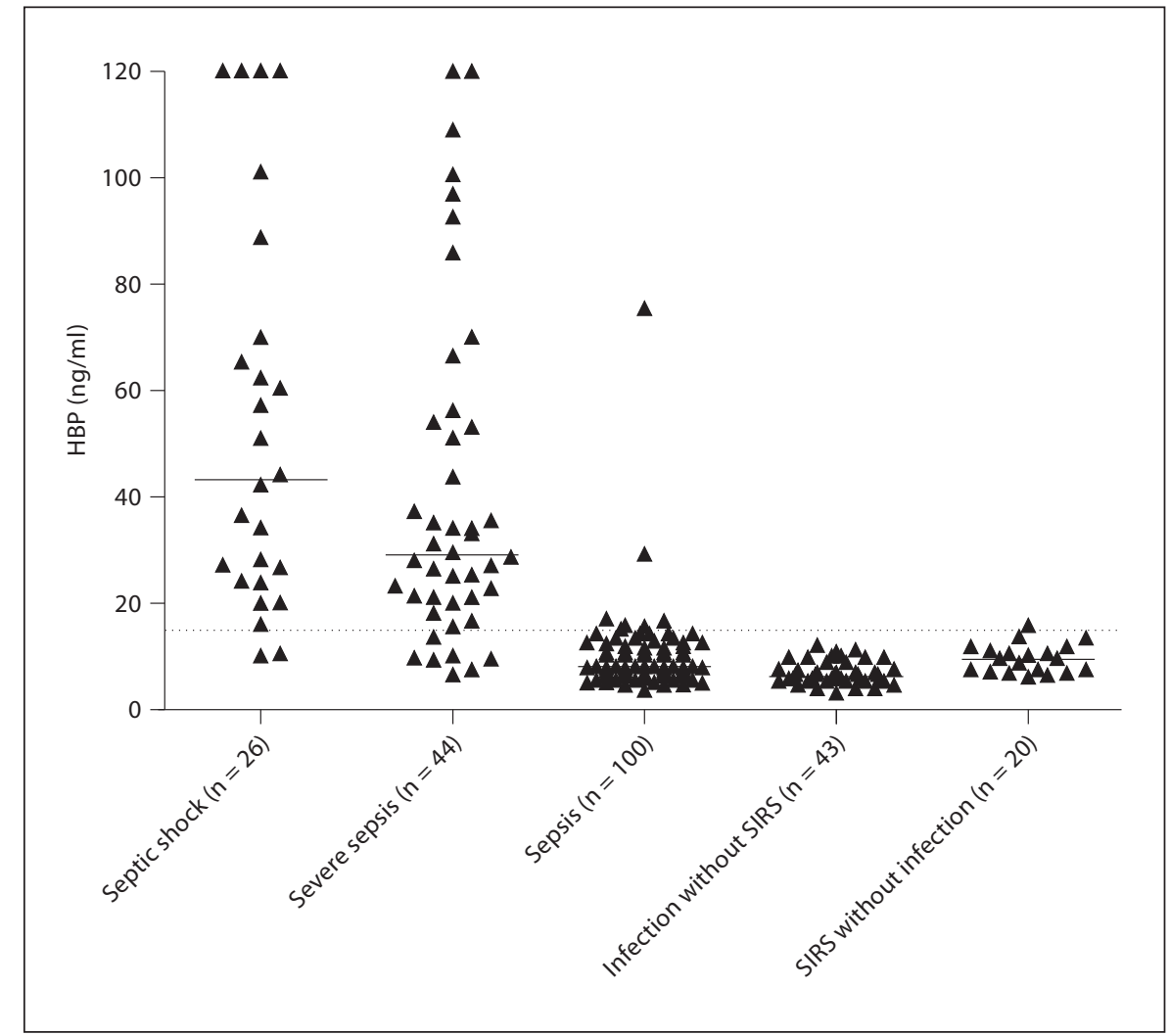

sequent lung damage and edema formation [33]. The fact that M1/fibrinogen complexes also activate neutrophils to degranulate in the circulation [30] suggests a role for HBP in the pathophysiology of sepsis (fig. 1).

The levels of plasma HBP during human infection were investigated in a prospective study of patients with fever who were admitted to a major hospital [34]. 233 subjects were enrolled and divided into 4 study groups according to standardized sepsis definitions [35]. Seventy of the patients fulfilled the criteria for severe sepsis: infection and systemic inflammatory response with hypotension and/or organ damage. Twenty-six of these had a more serious circulatory failure that was refractory to fluid treatment, and thus had septic shock. Study patients who did not have severe sepsis $(n=163)$ were classified into the diagnosis groups sepsis (infection and SIRS, but no circulatory failure), infection without SIRS, and SIRS of non-infectious etiology. The median plasma levels of HBP were higher among the patients who had or who developed severe sepsis than in patients with sepsis, milder infection or SIRS without infection (fig. 2). In fact, the median level for patients with non-severe infection was in line with measurements in healthy blood donors (5.5, range $2.5-9.1 \mathrm{ng} / \mathrm{ml})$, whereas the median level for patients with severe sepsis was significantly higher (44, range $7.5-494 \mathrm{ng} / \mathrm{ml}$ ). The strong association between high HBP concentrations and the development of sepsis with circulatory symptoms supports a role for HBP as a mediator of capillary leakage in clinical infection.

To estimate the value of HBP as a marker for sepsis, it was compared to previously studied biomarkers: procalcitonin, interleukin-6, C-reactive protein and lactate. All other markers displayed a similar pattern with higher levels in patients with severe sepsis; however, there were substantial overlaps between various patient groups. Plasma levels of HBP appeared to be the most robust parameter for differentiating patients with severe sepsis and circulatory failure from those with less severe infections. At a cutoff level of $15 \mathrm{ng} / \mathrm{ml}$, the sensitivity for HBP in diagnosing severe sepsis was $87 \%$ and the specificity $95 \%$.

In this context it was interesting to note that HBP levels in several patients with severe sepsis were elevated before a significant hypotension was detected. In some of these patients, plasma HBP levels were elevated up to $12 \mathrm{~h}$ before onset of hypotension. The white blood cell count (WBC) performed poorly in distinguishing be- 
tween severe sepsis and less serious infections which is in line with previous studies [36]. Furthermore, there was no correlation between HBP levels and WBC in the patient population, indicating that a specific neutrophil activation is required if $\mathrm{HBP}$ is to be released into the circulation.

A specific molecular mechanism for triggering HBP release by a bacterium has only been shown for $S$. pyogenes [30]. Whether or not a similar mechanism exists for other bacteria is unknown. However, among the 70 patients studied who had severe sepsis and septic shock, the bacterial etiology was determined in 46 cases [34]. Twenty-seven and 19 of the patients were infected by Grampositive and Gram-negative bacteria, respectively. Fifteen different bacterial species were isolated; 8 different Grampositive bacteria. Clearly, severe infections caused by a wide range of bacterial species leads to an increased plasma level of HBP. No significant difference was detected when HBP levels in patients infected by Gram-positive or Gram-negative bacteria were compared (unpublished data).

Several patients in this clinical study who did not have any infection still suffered from hypotension. In these cases, circulatory failure was attributed to, e.g., cardiac failure, gastrointestinal bleeding, and pulmonary embolism. None of these patients had an increased HBP level which underlines the specificity of the release during infection. However, one noninfectious condition that is accompanied by HBP release is severe burns. These injuries are associated with increased vascular permeability and edema formation. A study of 10 consecutive patients admitted to a burn unit showed that these patients had elevated HBP concentrations in plasma as compared to healthy controls [37]. HBP levels declined and reached almost normal levels within 24-48 h after the burn, known as the hyperpermeability phase, proposing a relationship between the HBP concentration in plasma and alterations in vascular permeability. This study was small but the results suggest that HBP may act as a mediator of the early burn-induced increase in vascular permeability.

\section{HBP Modulation as a Therapeutic Target}

Some molecular targets for intervening with HBP release have been identified. Gautam et al. [12] demonstrated that anti-HBP antibodies and aprotinin could attenuate neutrophil-evoked increase in vascular permeability. The HBP release induced by streptococcal M1 protein could be blocked by a $\beta_{2}$-integrin antagonist and a pep- tide (Gly-Pro-Arg-Pro) that interferes with the interaction between fibrinogen and $\beta_{2}$-integrins [30]. This peptide could also prevent severe lung lesions that developed in mice after M1 protein injection. Another interesting finding was that polyanion dextran sulfate completely prevented the effect of HBP on endothelial permeability when administered simultaneously [12]. Colloidal plasma expanders such as dextran sulfate are commonly used for fluid resuscitation in hypovolemic patients. Although it remains to be proven, some of the beneficial effects of dextran sulfate may be attributed to its interaction with $\mathrm{HBP}$. The heparin-binding property of $\mathrm{HBP}$ is also of interest. Animal and human models have suggested that heparin, in addition to successfully inhibiting the coagulation cascade, also modulates a wide array of responses to infection [38-42]. In three large clinical sepsis trials evaluating the effect of treatment with recombinant anticoagulants (antithrombin III, tissue factor inhibitor, activated protein $\mathrm{C}$ ), the use of prophylactic treatment for venous thrombosis was allowed [43-45]. Subanalysis of the patients in the placebo arms of these three studies (i.e. patients who did not receive experimental sepsis treatment) showed a lower mortality among patients who were given heparin. These data raise the question whether the increased survival in patients who received heparin could be an effect of the blocking of HBP, and the subsequent reduction in vascular leakage.

\section{Conclusion}

HBP is a neutrophil-derived protein that acts as an amplifier of inflammatory responses and induces capillary leakage. During sepsis there is a significant increase in HBP in plasma, and the levels correlate with the development of hypotension and circulatory failure. Although it remains to be confirmed in larger and more heterogeneous populations, the rapid assessment of HBP concentration could prove to be a valuable tool for the early diagnosis of severe sepsis. HBP is also elevated in the skin during soft tissue infections, and may contribute to the development of complications like edema. Therapeutic modulation of HBP is an interesting objective, which could prove useful in many conditions caused by bacterial infections. However, this still warrants further studies, particularly in determining whether such modulation would bypass important steps in the necessary physiological reaction to pathogens. 


\section{Conflicts of Interest}

Hansa Medical (Lund, Sweden) has filed patent applications on HBP as a diagnostic target, and A.L. and P.Å. are listed as 2 of the inventors. The patent application is pending. O.S. declares no competing financial interests.

\section{Acknowledgements}

The authors were supported by the Deutsche Forschungsgemeinschaft (SO876/3-1, FOR809), the German Heart Foundation/German Foundation of Heart Research, the START program within the Faculty of Medicine at the RWTH Aachen University, the Swedish Government Funds for Clinical Research (ALF), the University Hospital in Lund, and Hansa Medical AB. We want to thank Dr. Paul O'Toole at the University College Cork, Ireland, for helpful comments on the manuscript.

\section{References}

1 Hotchkiss RS, Karl IE: The pathophysiology and treatment of sepsis. N Engl J Med 2003; 348:138-150.

2 Martin GS, Mannino DM, Eaton S, Moss M: The epidemiology of sepsis in the United States from 1979 through 2000. N Engl J Med 2003;348:1546-1554

3 Rittirsch D, Flierl MA, Ward PA: Harmful molecular mechanisms in sepsis. Nat Rev Immunol 2008;8:776-787.

-4 Kumar A, Roberts D, Wood KE, Light B, Parrillo JE, Sharma S, Suppes R, Feinstein D, Zanotti S, Taiberg L, Gurka D, Kumar A, Cheang M: Duration of hypotension before initiation of effective antimicrobial therapy is the critical determinant of survival in human septic shock. Crit Care Med 2006;34: 1589-1596.

5 Marshall JC, Reinhart K: Biomarkers of sepsis. Crit Care Med 2009;37:2290-2298.

6 Shafer WM, Martin LE, Spitznagel JK: Cationic antimicrobial proteins isolated from human neutrophil granulocytes in the presence of diisopropyl fluorophosphate. Infect Immun 1984;45:29-35.

7 Yang D, de la Rosa G, Tewary P, Oppenheim JJ: Alarmins link neutrophils and dendritic cells. Trends Immunol 2009;30:531-537.

-8 Soehnlein O, Lindbom L: Neutrophil-derived azurocidin alarms the immune system. J Leukoc Biol 2009;85:344-351.

-9 Tapper H, Karlsson A, Morgelin M, Flodgaard $\mathrm{H}$, Herwald $\mathrm{H}$ : Secretion of heparinbinding protein from human neutrophils is determined by its localization in azurophilic granules and secretory vesicles. Blood 2002, 99:1785-1793.

10 Pereira HA, Shafer WM, Pohl J, Martin LE, Spitznagel JK: CAP37, a human neutrophilderived chemotactic factor with monocyte specific activity. J Clin Invest 1990;85:14681476.

11 Petersen LC, Birktoft JJ, Flodgaard H: Binding of bovine pancreatic trypsin inhibitor to heparin binding protein/CAP37/azurocidin. Interaction between a Kunitz-type inhibitor and a proteolytically inactive serine proteinase homologue. Eur J Biochem 1993;214:271279
2 Gautam N, Olofsson AM, Herwald H, Iversen LF, Lundgren-Akerlund E, Hedqvist P, Arfors KE, Flodgaard H, Lindbom L: Heparin-binding protein (HBP/CAP37): a missing link in neutrophil-evoked alteration of vascular permeability. Nat Med 2001;7: 1123-1127.

13 Soehnlein O, Zernecke A, Eriksson EE Rothfuchs AG, Pham CT, Herwald H, Bidzhekov K, Rottenberg ME, Weber C, Lindbom L: Neutrophil secretion products pave the way for inflammatory monocytes. Blood 2008;112:1461-1471.

14 Chertov O, Ueda H, Xu LL, Tani K, Murphy WJ, Wang JM, Howard OM, Sayers TJ, Oppenheim JJ: Identification of human neutrophil-derived cathepsin G and azurocidin/ CAP37 as chemoattractants for mononuclear cells and neutrophils. J Exp Med 1997;186: 739-747.

15 Strauss-Ayali D, Conrad SM, Mosser DM: Monocyte subpopulations and their differentiation patterns during infection. J Leukoc Biol 2007;82:244-252.

16 Auffray C, Sieweke MH, Geissmann F: Blood monocytes: development, heterogeneity, and relationship with dendritic cells. Annu Rev Immunol 2009;27:669-692.

17 Soehnlein O, Weber C: Myeloid cells in atherosclerosis: initiators and decision shapers. Semin Immunopathol 2009;31:35-47.

18 Soehnlein O, Weber C, Lindbom L: Neutrophil granule proteins tune monocytic cell function. Trends Immunol 2009;30:538546.

19 Pahlman LI, Morgelin M, Eckert J, Johansson L, Russell W, Riesbeck K, Soehnlein O, Lindbom L, Norrby-Teglund A, Schumann RR, Bjorck L, Herwald H: Streptococcal M protein: a multipotent and powerful inducer of inflammation. J Immunol 2006;177:12211228.

20 Soehnlein O, Kai-Larsen Y, Frithiof R, Sorensen OE, Kenne E, Scharffetter-Kochanek K, Eriksson EE, Herwald H, Agerberth B, Lindbom L: Neutrophil primary granule proteins HBP and HNP1-3 boost bacterial phagocytosis by human and murine macrophages. J Clin Invest 2008;118:3491-3502.
21 Mosser DM, Edwards JP: Exploring the full spectrum of macrophage activation. Nat Rev Immunol 2008;8:958-969.

22 Soehnlein O: Direct and alternative antimicrobial mechanisms of neutrophil-derived granule proteins. J Mol Med 2009;87:11571164.

23 Lee TD, Gonzalez ML, Kumar P, Grammas P, Pereira HA: CAP37, a neutrophil-derived inflammatory mediator, augments leukocyte adhesion to endothelial monolayers. Microvasc Res 2003;66:38-48.

24 Wedmore CV, Williams TJ: Control of vascular permeability by polymorphonuclear leukocytes in inflammation. Nature 1981; 289:646-650.

25 Arfors KE, Lundberg C, Lindbom L, Lundberg K, Beatty PG, Harlan JM: A monoclonal antibody to the membrane glycoprotein complex CD18 inhibits polymorphonuclear leukocyte accumulation and plasma leakage in vivo. Blood 1987;69:338-340.

26 Gautam N, Herwald H, Hedqvist P, Lindbom L: Signaling via beta(2) integrins triggers neutrophil-dependent alteration in endothelial barrier function. J Exp Med 2000;191: 1829-1839.

27 DiStasi MR, Ley K: Opening the flood-gates: how neutrophil-endothelial interactions regulate permeability. Trends Immunol 2009;30:547-556.

28 Di Gennaro A, Kenne E, Wan M, Soehnlein O, Lindbom L, Haeggstrom JZ: Leukotriene B4-induced changes in vascular permeability are mediated by neutrophil release of heparin-binding protein (HBP/CAP37/azurocidin). FASEB J 2009;23:1750-1757.

29 Iversen LF, Kastrup JS, Bjorn SE, Rasmussen PB, Wiberg FC, Flodgaard HJ, Larsen IK: Structure of HBP, a multifunctional protein with a serine proteinase fold. Nat Struct Biol 1997;4:265-268

30 Herwald H, Cramer H, Morgelin M, Russell W, Sollenberg U, Norrby-Teglund A, Flodgaard $\mathrm{H}$, Lindbom L, Bjorck L: M protein, a classical bacterial virulence determinant, forms complexes with fibrinogen that induce vascular leakage. Cell 2004;116:367-379. 
31 Linder A, Johansson L, Thulin P, Hertzen E, Morgelin M, Christensson B, Bjorck L, Norrby-Teglund A, Akesson P: Erysipelas caused by group A streptococcus activates the contact system and induces the release of heparin-binding protein. J Invest Dermatol 2010 [Epub ahead of print].

32 Lundqvist K, Herwald $\mathrm{H}$, Sonesson A, Schmidtchen A: Heparin binding protein is increased in chronic leg ulcer fluid and released from granulocytes by secreted products of Pseudomonas aeruginosa. Thromb Haemost 2004;92:281-287.

-33 Soehnlein O, Oehmcke S, Ma X, Rothfuchs AG, Frithiof R, van Rooijen N, Morgelin M, Herwald H, Lindbom L: Neutrophil degranulation mediates severe lung damage triggered by streptococcal M1 protein. Eur Respir J 2008;32:405-412.

- 34 Linder A, Christensson B, Herwald H, Bjorck L, Akesson P: Heparin-binding protein: an early marker of circulatory failure in sepsis. Clin Infect Dis 2009;49:1044-1050.

- 35 American College of Chest Physicians/Society of Critical Care Medicine Consensus Conference: Definitions for sepsis and organ failure and guidelines for the use of innovative therapies in sepsis. Crit Care Med 1992; $20: 864-874$.
36 Davis BH, Olsen SH, Ahmad E, Bigelow NC: Neutrophil CD64 is an improved indicator of infection or sepsis in emergency department patients. Arch Pathol Lab Med 2006; 130:654-661.

37 Johansson J, Lindbom L, Herwald H, Sjoberg F: Neutrophil-derived heparin binding protein - a mediator of increased vascular permeability after burns? Burns 2009;35:11851187.

38 Griffin MP, Gore DC, Zwischenberger JB, Lobe TE, Hall M, Traber DL, Herndon DN: Does heparin improve survival in experimental porcine gram-negative septic shock? Circ Shock 1990;31:343-349.

39 Tanaka T, Tsujinaka T, Kambayashi J, Higashiyama M, Yokota M, Sakon M, Mori T: The effect of heparin on multiple organ failure and disseminated intravascular coagulation in a sepsis model. Thromb Res 1990;60: 321-330.

40 Boldt J, Papsdorf M, Piper SN, Rothe A, Hempelmann G: Continuous heparinization and circulating adhesion molecules in the critically ill. Shock 1999;11:13-18.

41 Meyer J, Cox CS, Herndon DN, Nakazawa H, Lentz CW, Traber LD, Traber DL: Heparin in experimental hyperdynamic sepsis. Crit Care Med 1993;21:84-89.
42 Pernerstorfer T, Hollenstein U, Hansen J, Knechtelsdorfer M, Stohlawetz P, Graninger W, Eichler HG, Speiser W, Jilma B: Heparin blunts endotoxin-induced coagulation activation. Circulation 1999;100:2485-2490.

43 Warren BL, Eid A, Singer P, Pillay SS, Carl P, Novak I, Chalupa P, Atherstone A, Penzes I, Kubler A, Knaub S, Keinecke HO, Heinrichs H, Schindel F, Juers M, Bone RC, Opal SM: Caring for the critically ill patient. Highdose antithrombin III in severe sepsis: a randomized controlled trial. JAMA 2001;286: 1869-1878.

44 Abraham E, Reinhart K, Opal S, Demeyer I, Doig C, Rodriguez AL, Beale R, Svoboda P, Laterre PF, Simon S, Light B, Spapen H, Stone J, Seibert A, Peckelsen C, De Deyne C, Postier R, Pettila V, Artigas A, Percell SR, Shu V, Zwingelstein C, Tobias J, Poole L, Stolzenbach JC, Creasey AA: Efficacy and safety of tifacogin (recombinant tissue factor pathway inhibitor) in severe sepsis: a randomized controlled trial. JAMA 2003;290:238-247.

45 Bernard GR, Vincent JL, Laterre PF, LaRosa SP, Dhainaut JF, Lopez-Rodriguez A, Steingrub JS, Garber GE, Helterbrand JD, Ely EW, Fisher CJ Jr: Efficacy and safety of recombinant human activated protein $\mathrm{C}$ for severe sepsis. N Engl J Med 2001;344:699-709. 